\title{
المؤتمر الدّولي الأوّل لتعليم اللغة العربية للناطقين بغيرها المنعقد بمر كز اللغات بالجامعة الأردنيّة / عمّان - الأردن

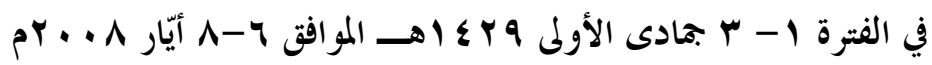

خالد حسين أبو عمشة * - ( )

تحت رعاية الأستاذ الدكتور خالد الكركي رئيس الجامعة الأردنية أقامت كليسـة

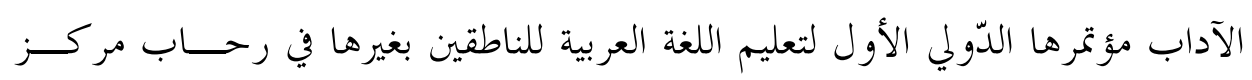

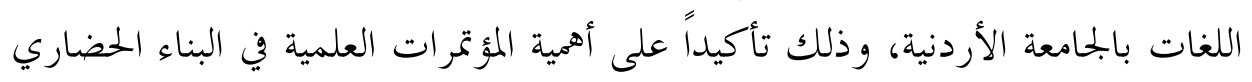

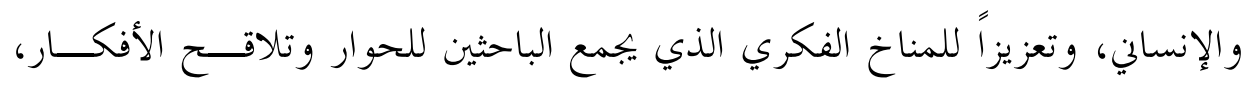

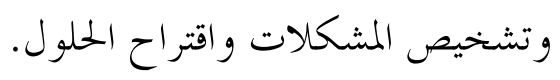

وهدف المؤتمر إلى البحث في محاور تتعلق بتعليم اللغة العربية للناطقين بغيرها، ومن

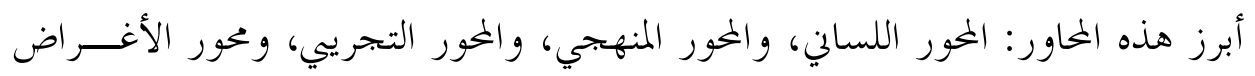
الخاصة وعلاقتها بتعليم العربية للناطقين بغيرها. وقد عقدت جلسات المؤتمر التسع على مدى ثلاثة أيّام، وشارك في أعمالها واحد

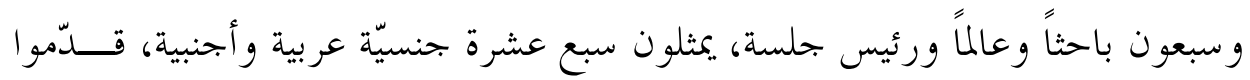

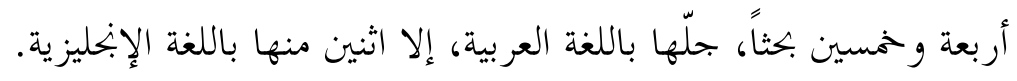

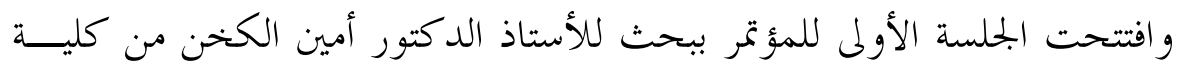

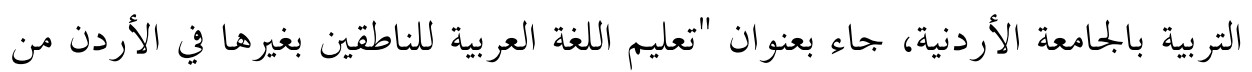

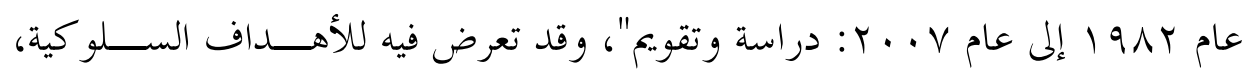

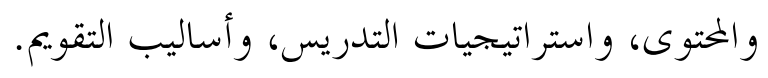

abuamsha@gmail.com دكتوراه في مناهج اللغة العربية وطرائق تدريسها للناطقين بغيرها. 
أمّا البحث الثاني فكان للدكتور نيقولاي بانتيوخين من جامعة موسكو للعلاقات

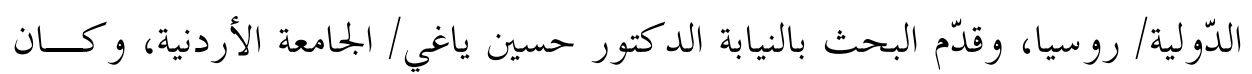

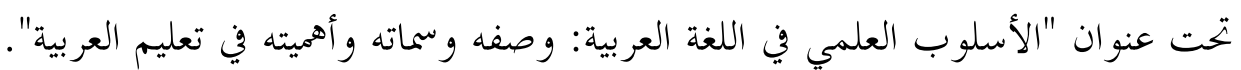

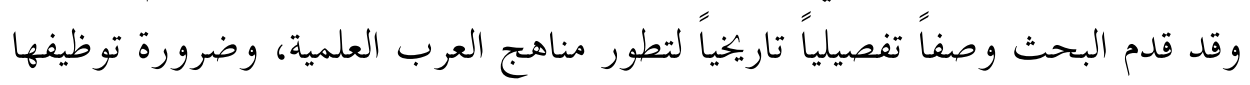
في تعليم العر بية للناطقين بغيرها.

أمّا البحث الثالث فكان للدكتورة بسمة الدّجاني/ الجحامعة الأردنية، وجاء بعنوان:

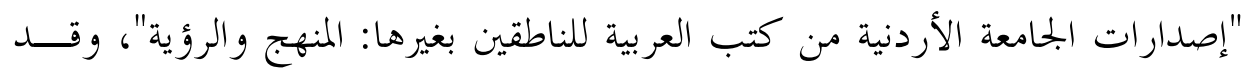

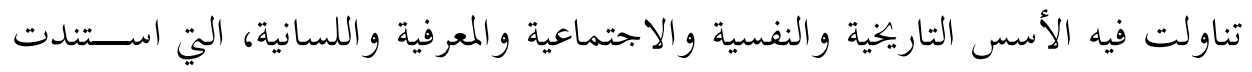

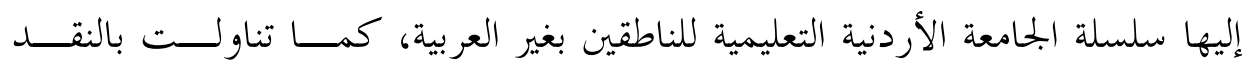
و التحليل موضوعاها من حيث: المحلية، والإقليمية، و العالمية.

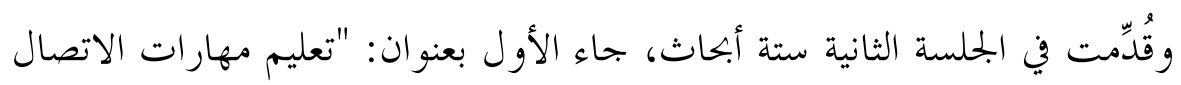

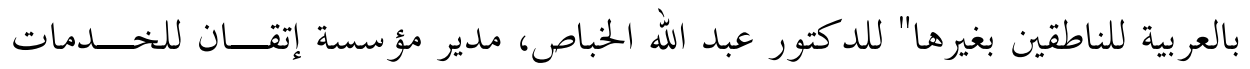

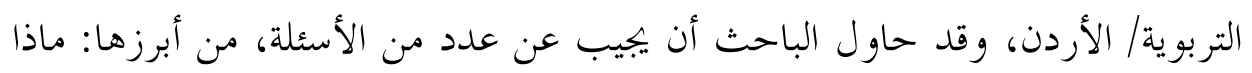

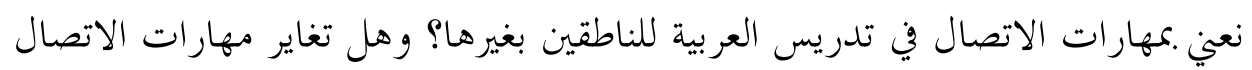

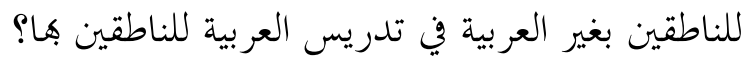
أمّا البحث الثاني فجاء بعنوان "مقترح لمعالجة المفردات الجلديدة في نصوص القراءة

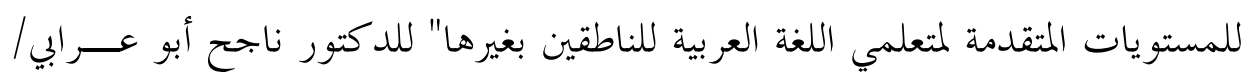

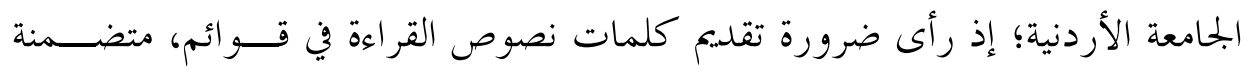

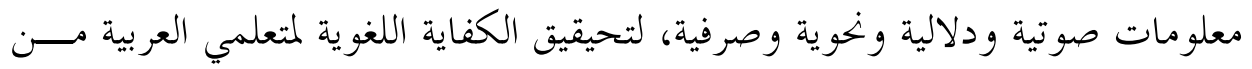
الناطقين بغيرها، وذلك على مستوى الكلمة الو احدة. أمّا كيفية تعلّم لفظ الأصوات الجلديدة في بحال تدريس اللغة العربيـــة للنــاطقين

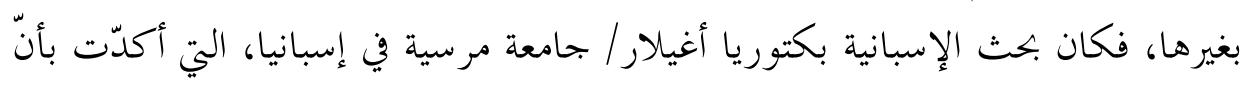


الطلبة الإسبان سيبقون يعانون من صعو بات في نطق العربية، بسبب تعقيــــات هـــــه

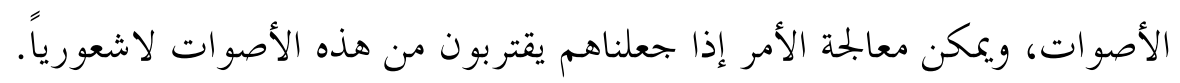
وقدّمت الدكتورة نئ حنان مصطفى، والدكتورة نئ فرحان مصطفى، و الدكتورة

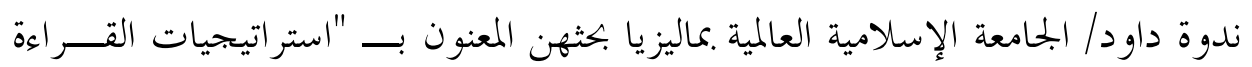

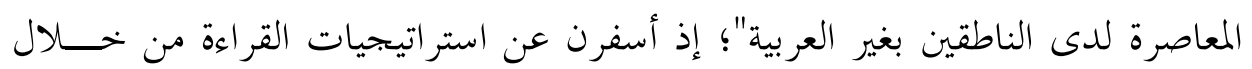

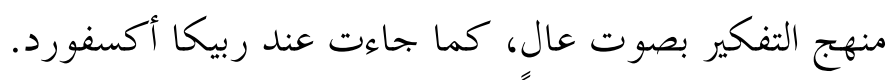
وقدّمت الدكتورة ابتسام حسين جهيل، من جامعة الإسراء/ الأردن بحثناً بعنـــوان:

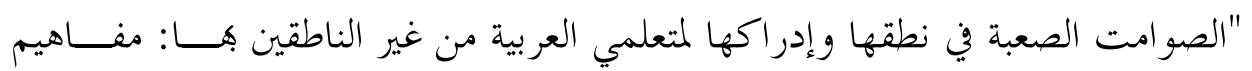

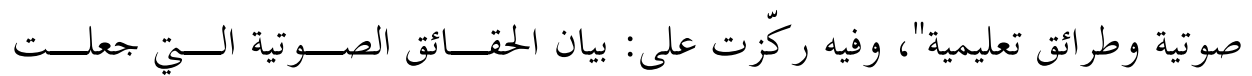
الأصوات الحلقية تتسم بدرجة غير بسيطة من الصعوبة، والطرق التعليمية التعلّمية التي تصيّي تعين متعلم اللغة العربية على بتحاوز مشكلة ضياع الحمود الفاصلة بين الصوامت.

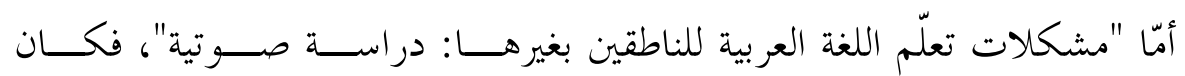

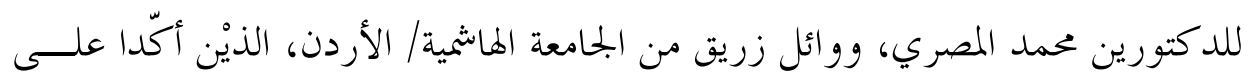

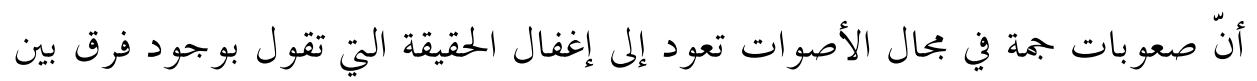
الصوامت في الحركات التي تسبقها أو تتبعها.

وقدّمت في الجلسة الثالثة ستّة أبحاث، كان الأول بعنوان: "قياس مقروئية كتــب

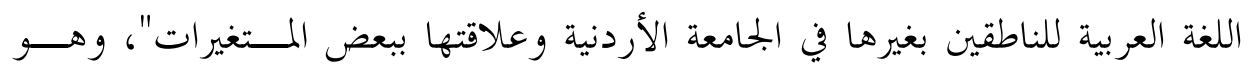

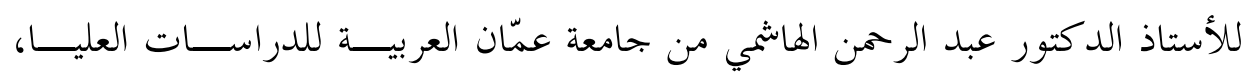
كمشاركة الدكتورة فائزة العزاوي من جامعة بغداد. وهدفت دراسة الباحثين إلى قياس

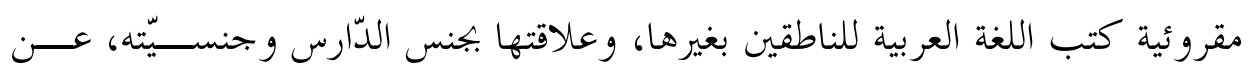
طريق اختبار الــ Close test.

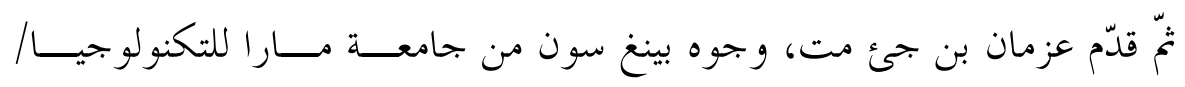

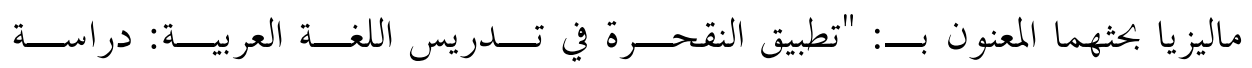


استطلاعيّة". و النقحرة كلمة منحوتة من "نقل الحرف"، أي الكتابة الصوتية بالحروف

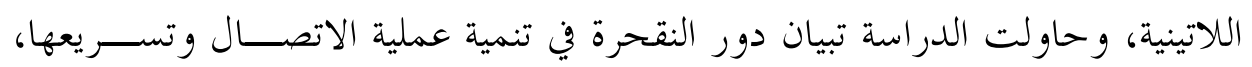
وأثرها على اللغة العربية الفصحى.

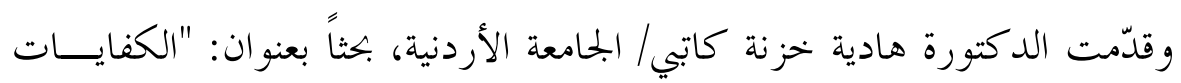

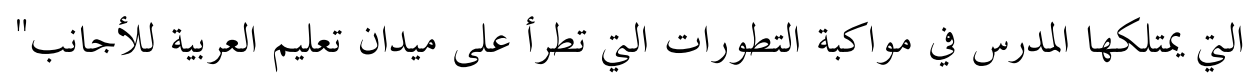

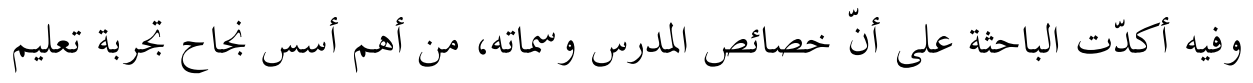
اللغة العر بية للناطقين بغيرها.

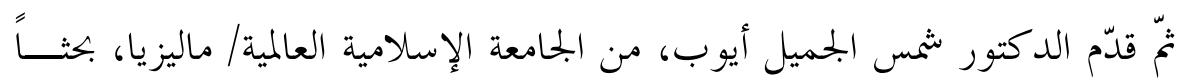

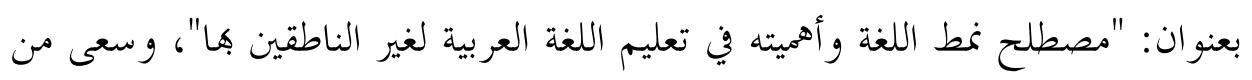

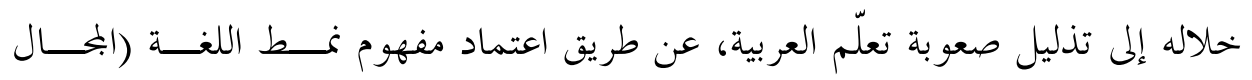

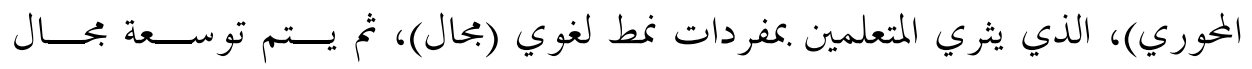
دراسته.

وتلا ذلك بحث "اللجوء إلى الترجمة كوسيلة من وسائل تعليم اللغة العربية لغسير

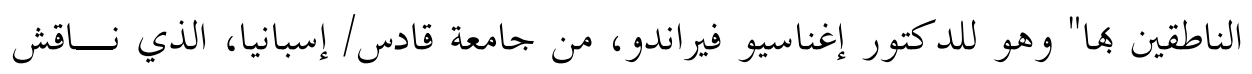

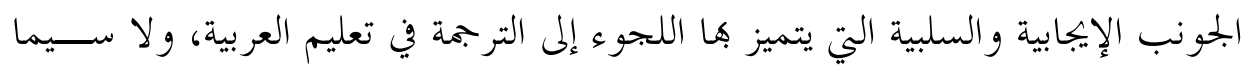
فيما يتعلق بالمستويات المتوسطة والعالية. وآخر بحوث هذه الجلسة، جاء بعنوان: "أهمية شبكة المعلومات العالمية في تعلــيم

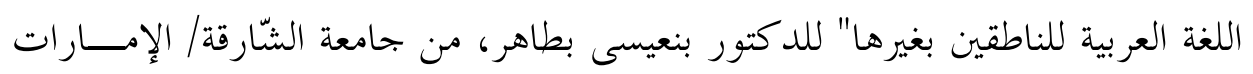

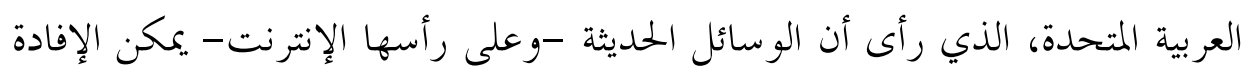

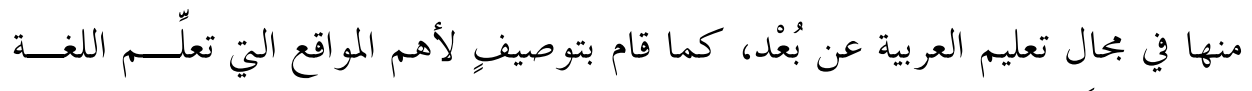
العر بية بحاناً.

أمّا الجلسة الخامسة فقد انعقدت ضمن جلسات اليوم الثاني، وتم فيها تقديم ســــة

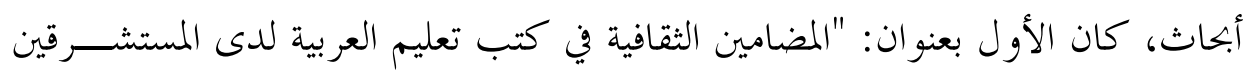


الألمان" للأستاذ الدكتور إسماعيل عمايرة/ الجامعة الأردنية، الذي رصد تطور تعلــيم

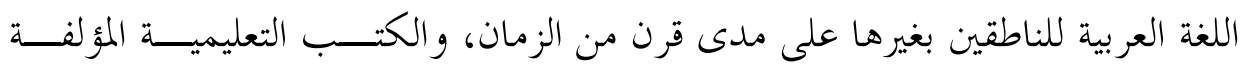

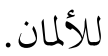

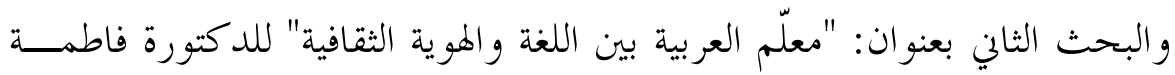

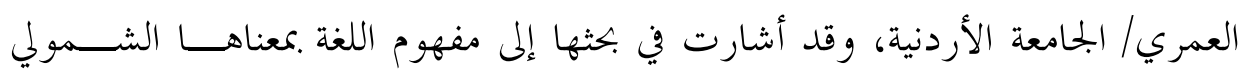

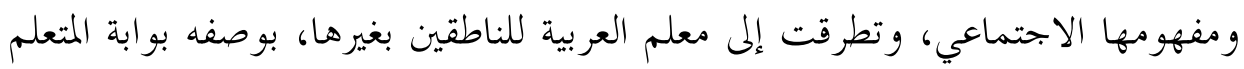
على البحتمع العربي، ولغته، وتثقافته، وهو ويته. وتحدّث الدكتور رائد عكاشة من جامعة الإسراء/ الأردن عن "المضمون الفكري

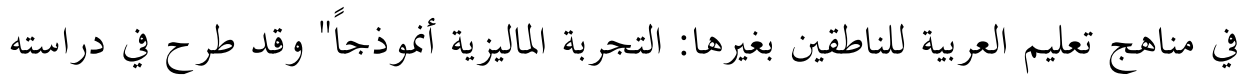

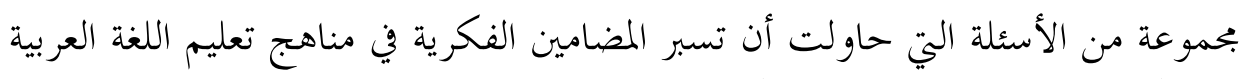

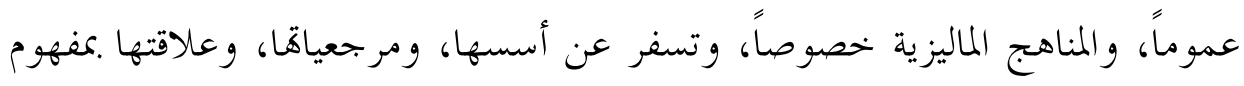

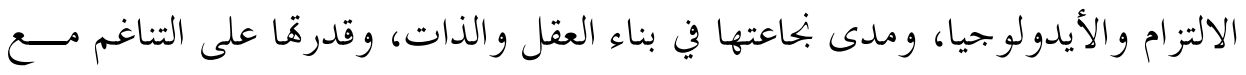
الثقافات البحتمعات الإسلامية غير العربية.

وجاء البحث الرّابع بعنوان: "اعتقادات تعلم اللغة العربية وتعلميها لدى دارسيها

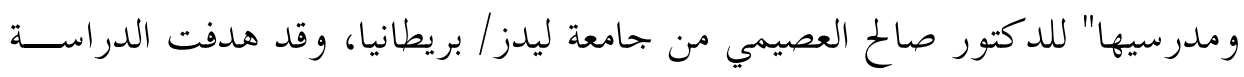

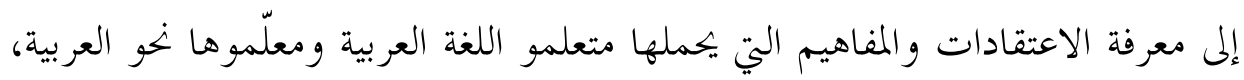
وأثر ذلك على العملية التعليمية.

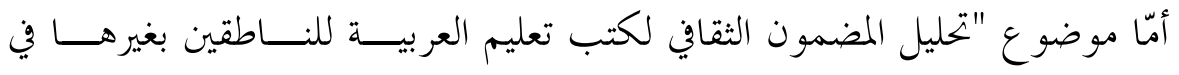

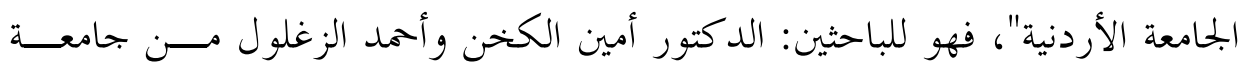

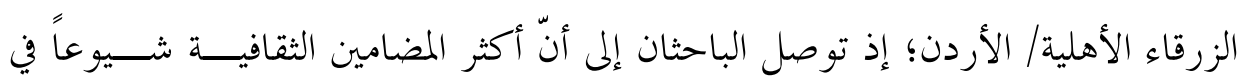

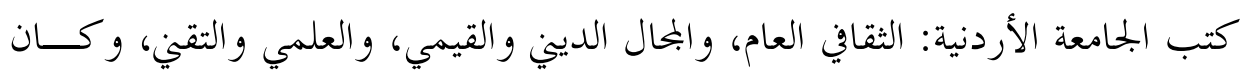

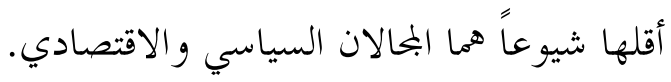


وجاء البحث السادس بعنوان: "قو اعد الاشتباك: تعليم اللغة العربية وثقافتــهـا في

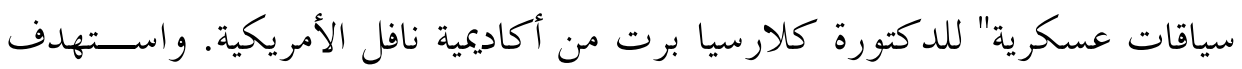

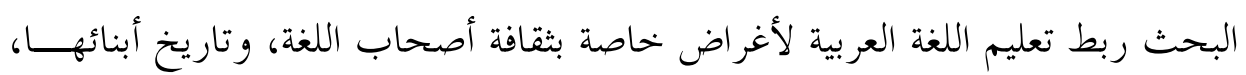
وفضّ الاشتباك بينها و بين ثقافة المتعلّم وتاريخه.

واحتوت الجلسة الخامِسة خمس أوراق، بُدئت بورقة الأستاذ الدكتور داود عبده

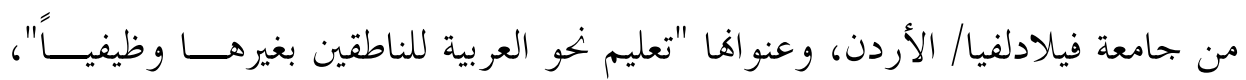

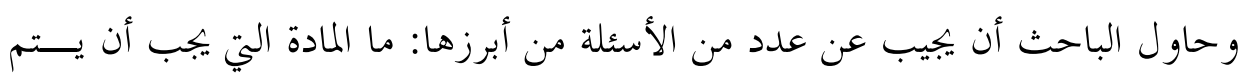

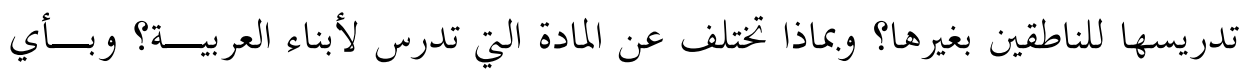

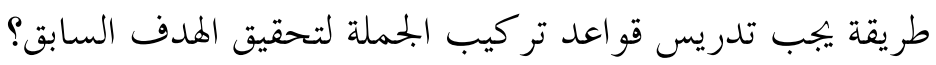
أمّا الورقة الثانية فكانت للدكتور حسين ياغي/ الجامعة الأردنية، وهي بعنـــــان:

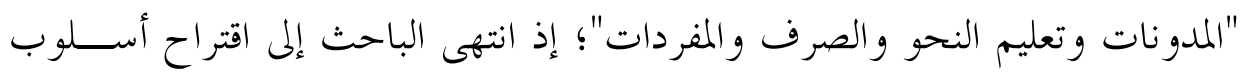

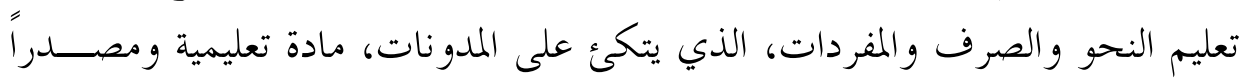
لاكتشاف القاعدة النحوية والصرفية.

أمّا البحث الثالث فقد كان للباحث خالد أبو عمشة، رئيس قسم اللغة العربية في

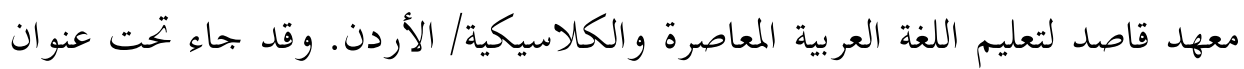

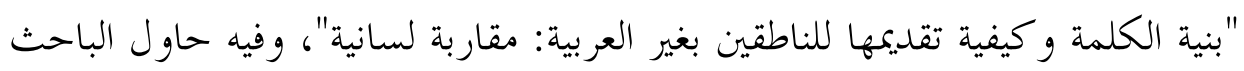

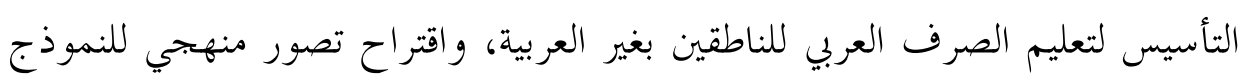

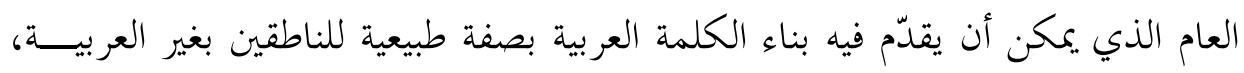

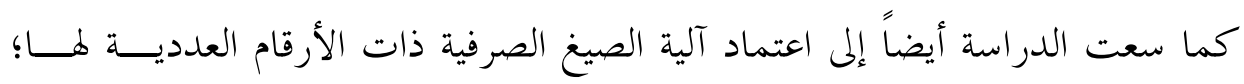

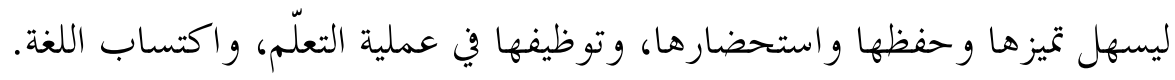

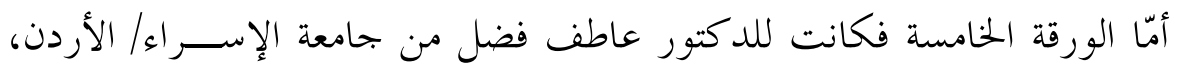

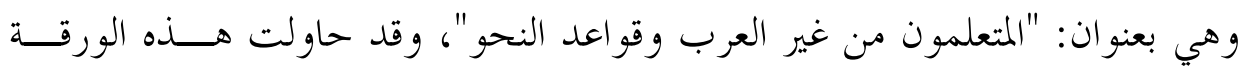


الإجابة عن السؤال المركزي التالي: كيف يجب أن يكون تعليم النحو العربي للناطقين بغير العربية من حيث: المرسل، والمستقبل، و الوسائل.

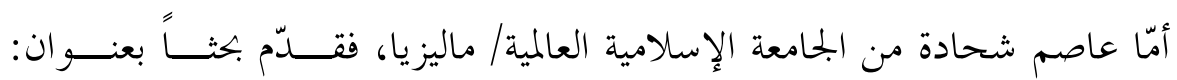

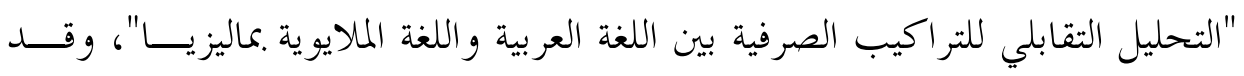

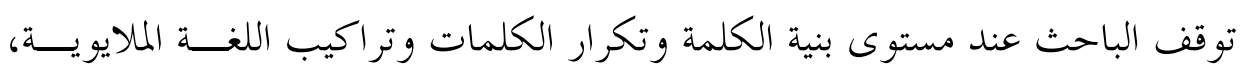
فيما أمعن النظر في المورفيم، والاشتقاق، والتصريف، وستوك والإعراب في العربية.

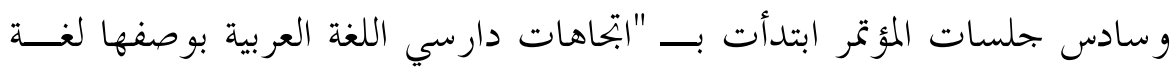

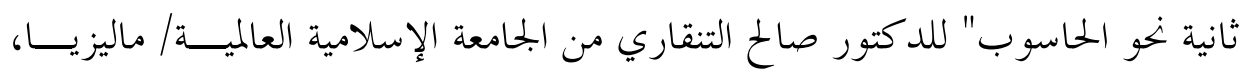

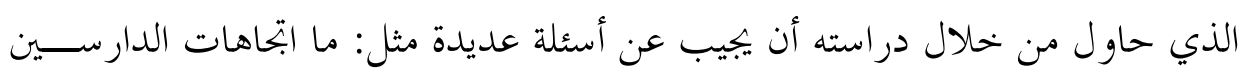

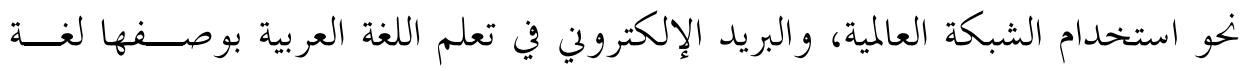

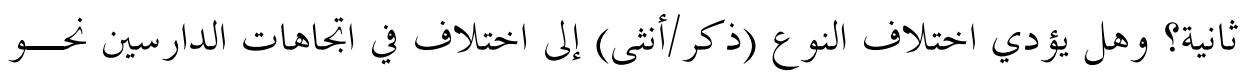
الحاسوب؟

أمّا "تسخير المواقع العربية لتعليم اللغة العربية للناطقين بغيرها في ماليزيا"، فكــان

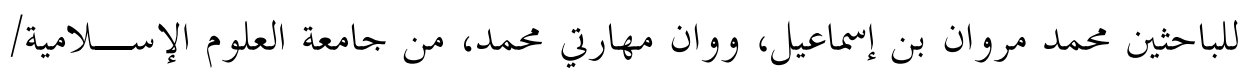

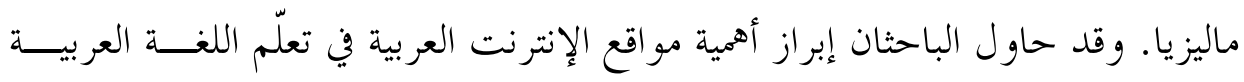

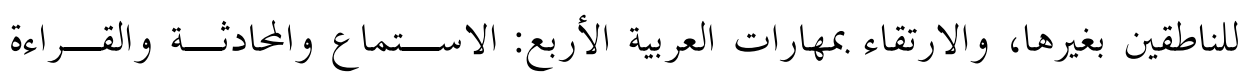
والكتابة، وعناصر اللغة العربية: نحوها وصرفها.

ومن جامعة أرض السنديان / أمريكا، قدّم الدكتور بنجامين وهبة الله حافِظ بحثاً

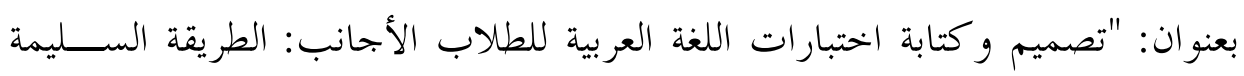

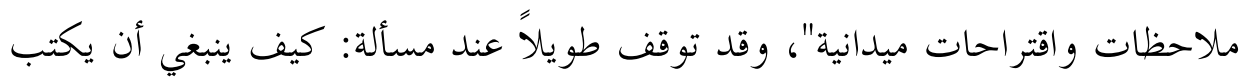

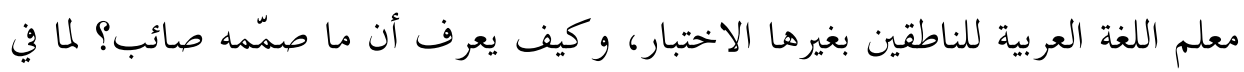
ذكر من تأثير إيجابي على سير العملية التعلميّة التعليمية. 


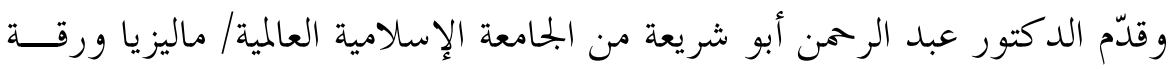

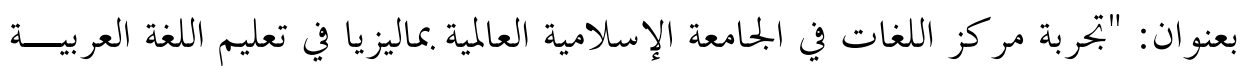

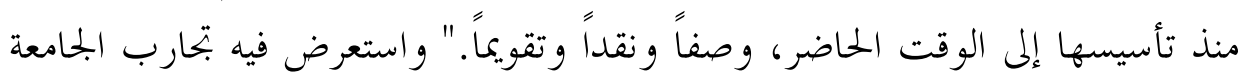

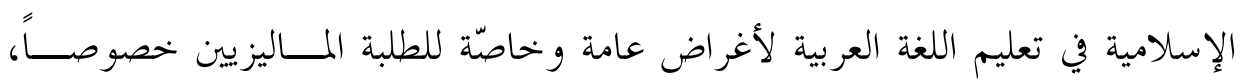
و الطلبة غير الماليزيين عموماً.

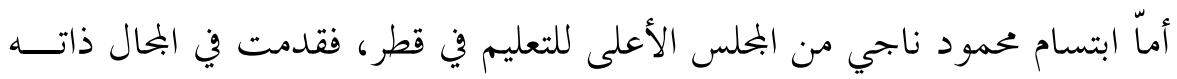

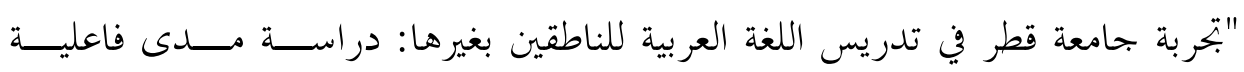

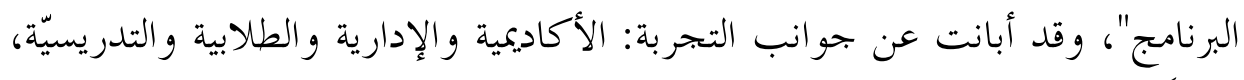
فضلاً عن توجهات الطلبة نحو البرنامج واللغة العربية.

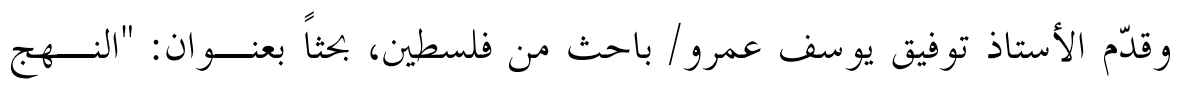

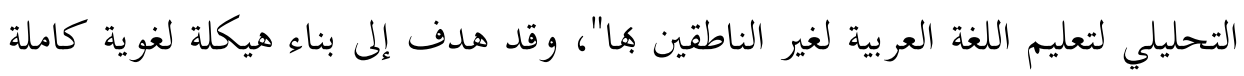

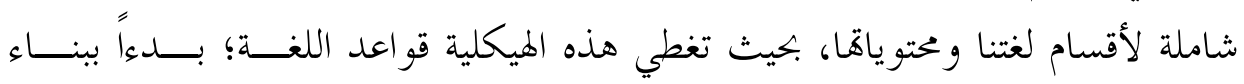
الحرف، و انتهاء ببناء الجملة.

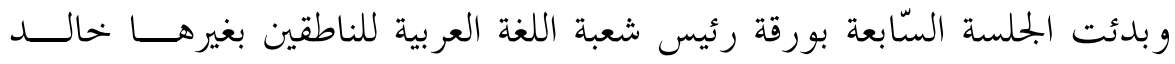

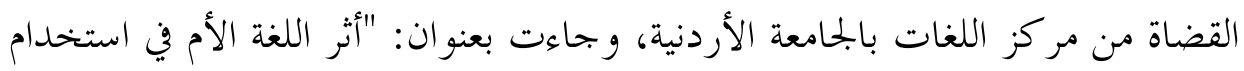

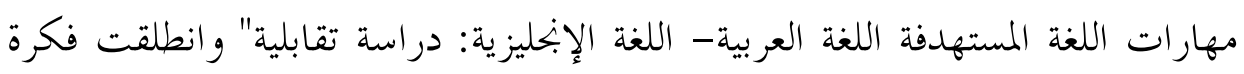

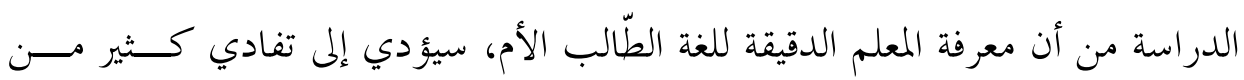
الأخطاء التي يقع فيها الطّلاب في المراحل الأولى لتعلم اللغة.

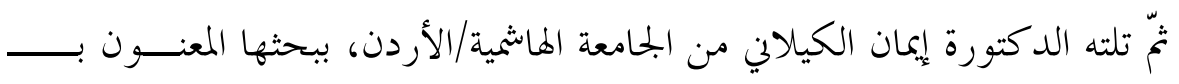

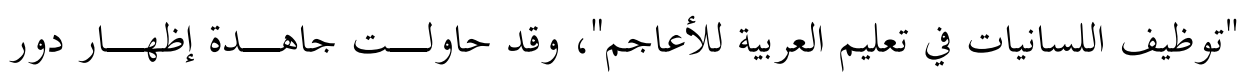

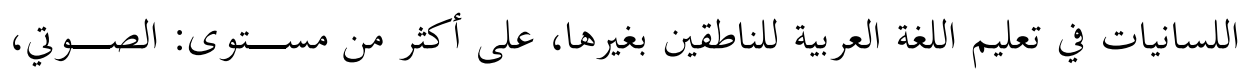
والكتابي، والمعجمي الدلالي، و التركيبي. 


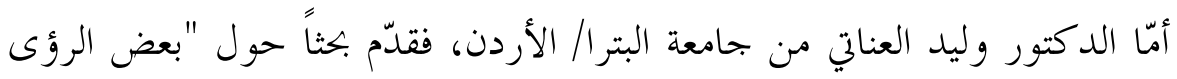

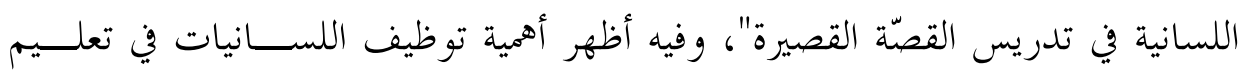
القصة، بوصفها فرعاً من فروع الأدب للناطقين بغير العربية.

أمّا بحث "المغامرة البلاغية في تعليم العربية للناطقين بغيرها" فكان للدكتور مصلح

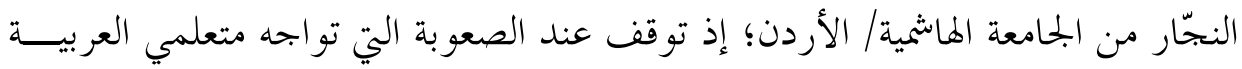

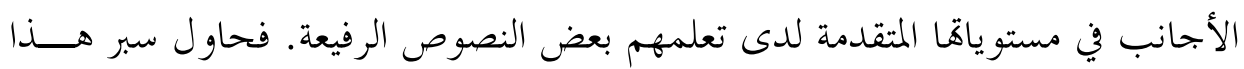

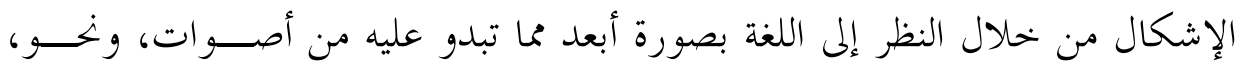
وصرف.

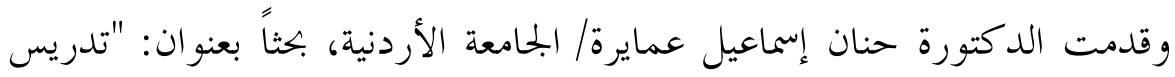

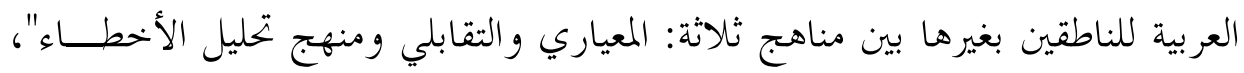

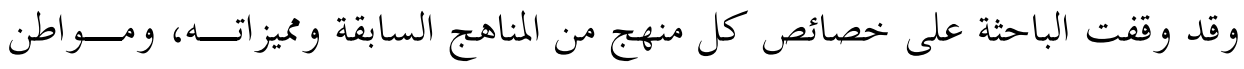

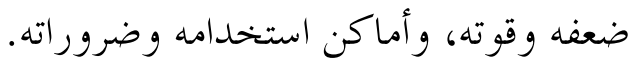

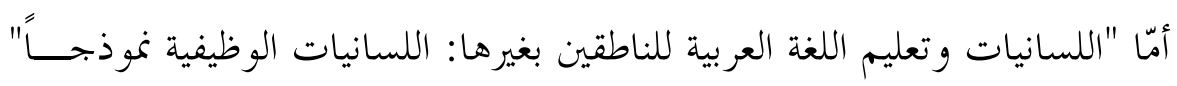

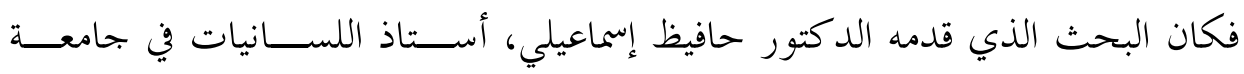

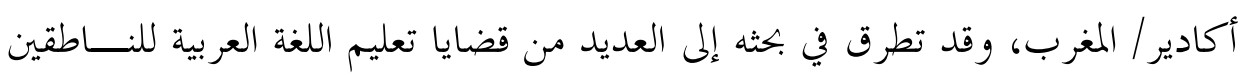
بغيرها من وجهة نظر وظيفية، وذلك على المستو يين النظري و العملي. وابتدأت الجلسة الثامنة ببحث "بتربة جامعة جين جي التايوانية في تعليم العربيــة

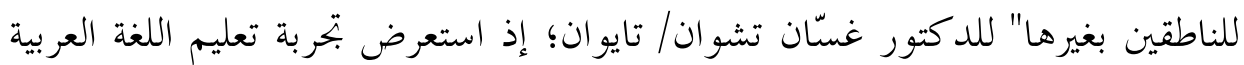

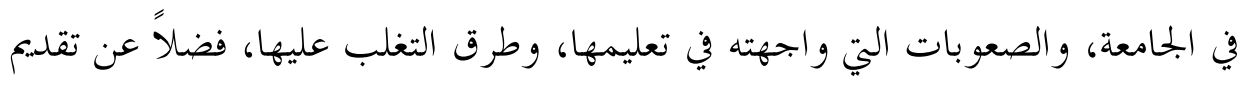
تاريخ موجز للغة العربية وتعليمها في تلك الجزيرة.

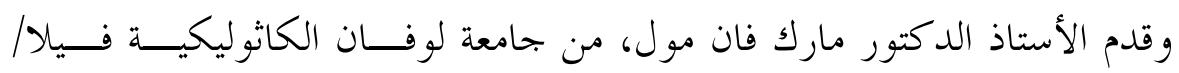

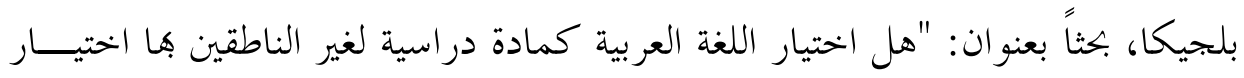

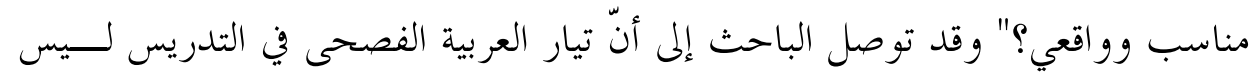


اختياراً مناسباً فحسب، بل هو اختيارٌ واقعي. أمّا الدكتورة ساندي أبو سيف/ الجحامعة

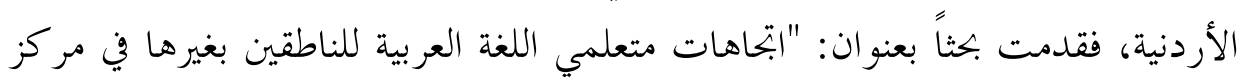

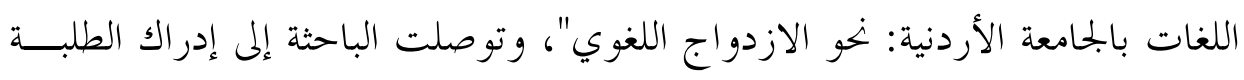

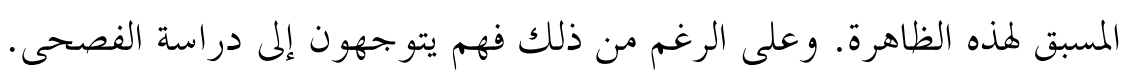
أمّا بحث "تحديات تو اجه الطلبة الأجانب ومدرسي اللغة العربية كلغـــة ثانيـــة في

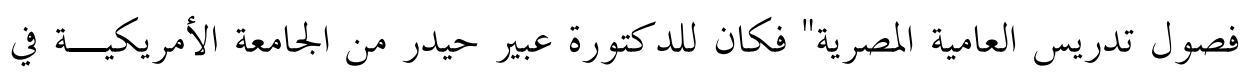

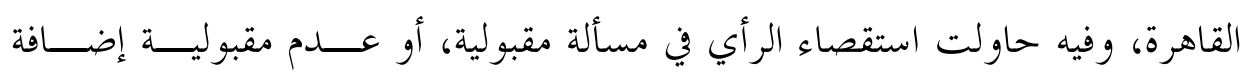

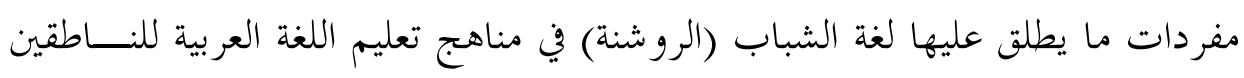
بغيرها.

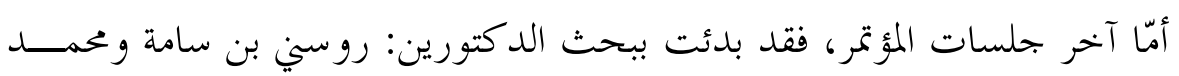

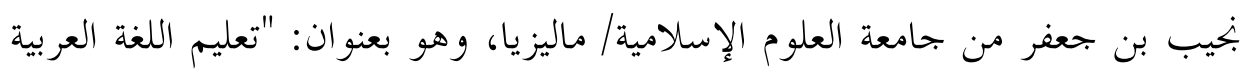

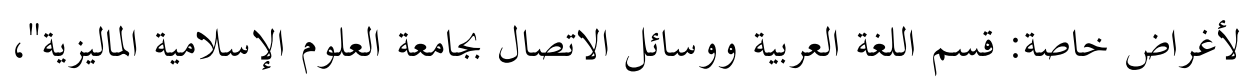

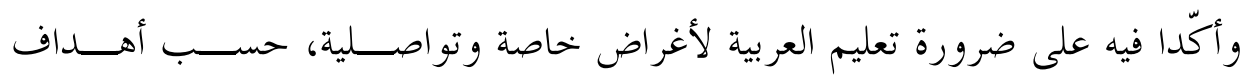

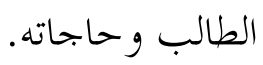

وقدمت الدكتورة رشا الهواري من جامعة الإسكندرية/ مصـــر، بحثــاً بعنـــــان:

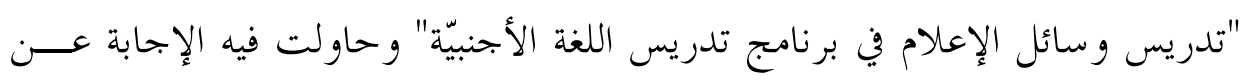

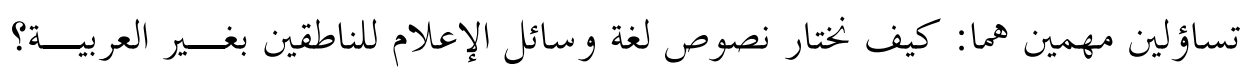

$$
\text { وكيف ندرسها؟ تهاولين }
$$

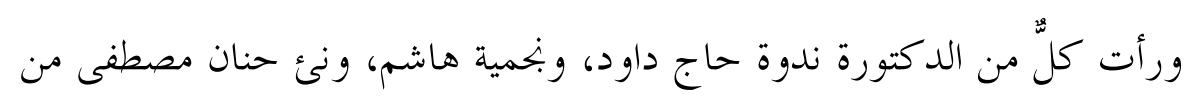

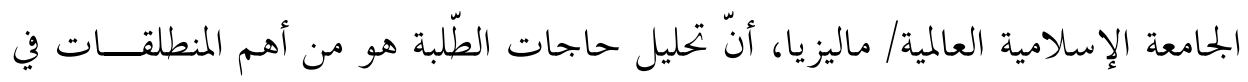

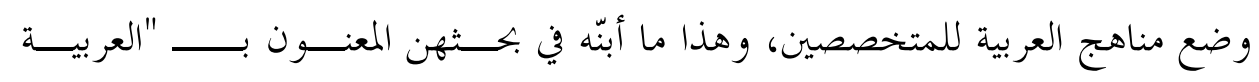

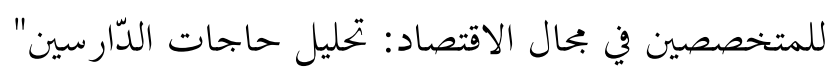


أمّا "خصوصيّة تعليم اللغة العربية للطّلبة الإسبان"، فهو بحث للدكتور وليد صالح|

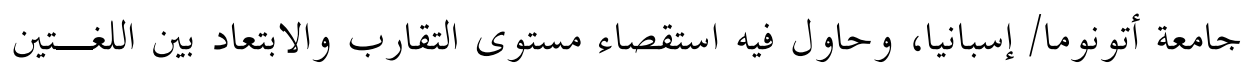

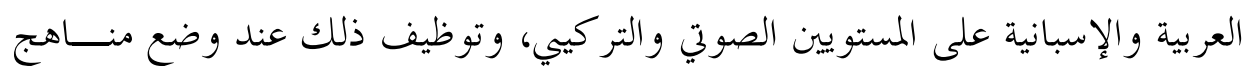
تعليم اللغة العربية للإسبان.

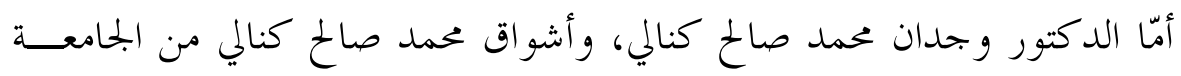

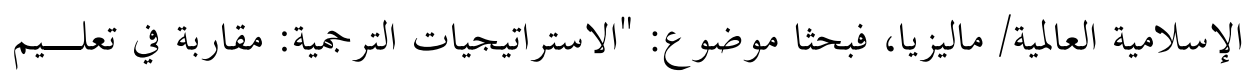

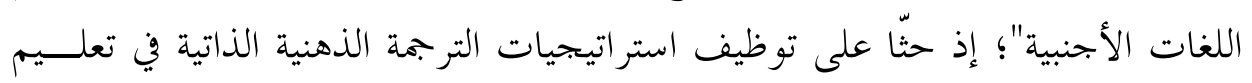
اللغة العر بية للناطقين بغيرها.

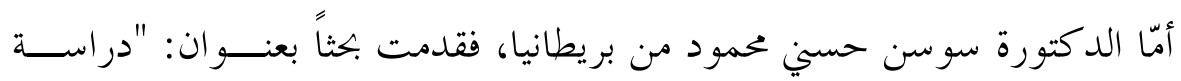

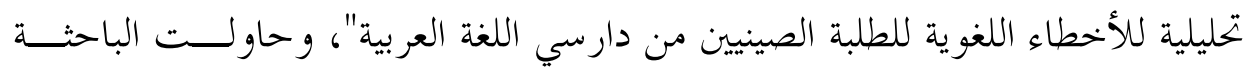

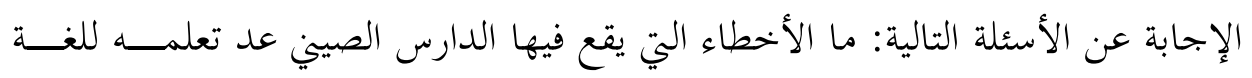

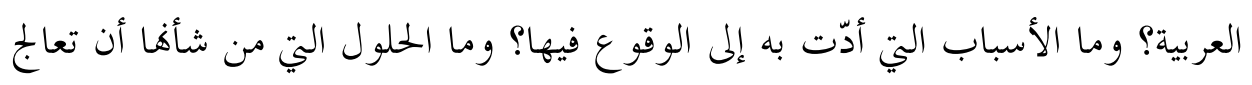
هذه المشكلة؟

وقدم الدكتور غسان الشاطر من جامعة أستراليا الوطنية، بحثاً بعنوان: "توظيــف فئف

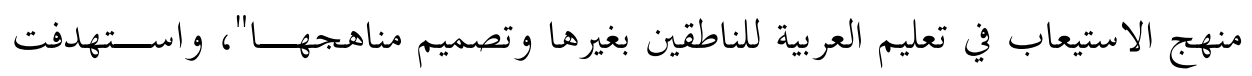

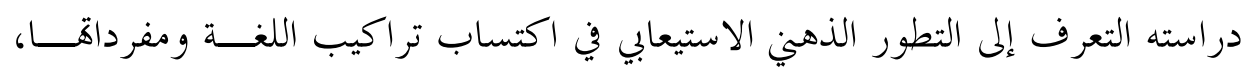
بوصفها لغة ثانية، وعلاقتها بالتدريس الفصلي الفعّال.

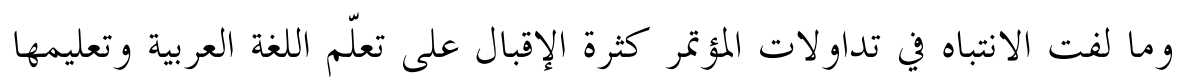

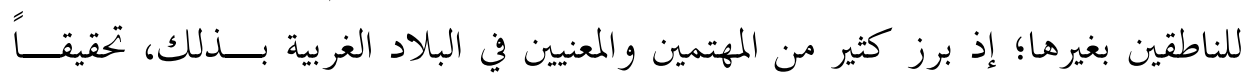

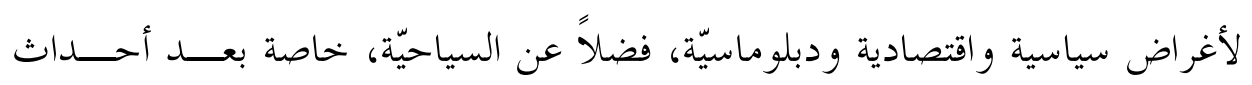

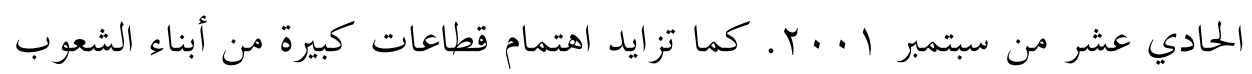

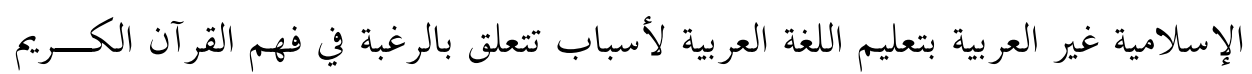

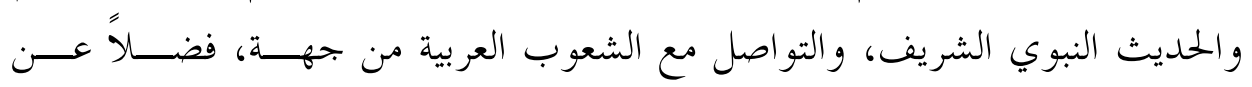

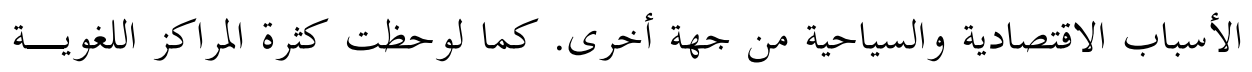


التي أخذت على عاتقها مهمة تعليم اللغة العربية للناطقين بغيرها، وتنافسها في ذلـــك،

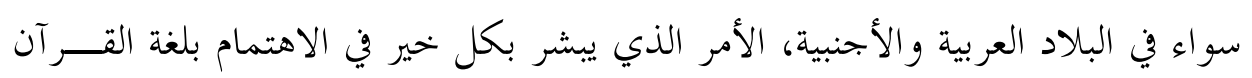
و القيام على نشرها، و تيسير تعليمها.

و وجاءت الجلسة الختامية للمؤتمر، لتلخص أهـــم مـــا دار في الجلســـات، وأهـــم

$$
\text { التوصيات، و كان من أبرزها: }
$$

- عقد المؤتمر سنوياً ليتسنى للعاملين في هذا الميدان الإفادة والاستفادة من كل ما هو جديد في هذا البحال.

- تأسيس رابطة لمدرسي اللغة العربية الناطقين بغيرها، يكون مقرها في الجامعسـة الأردنية، وأخرى إلكترو نية للأساتذة و المهتمين هذا راسئة الميدان.

- أكّد المؤتمرون على أهمية تعليم اللغة العربية للناطقين بغيرها ومُعَلِّمها في مـــدّ جسور التعاون و التفاهم بين الأمهم والشعوب، و بخاصة الشعوب الإسلامية غير العربية. - نوّه المؤتمرون إلى أهمية بذل الجهود في إخراج مناهج لتعليم العربية للنــاطقين

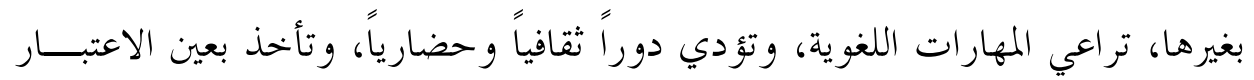

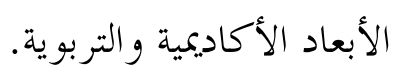

- إنشاء بحلة علمية دولية محكمة تختص بقضايا تعليم العربية للناطقين بغيرها. 